Gut, 1986, 27, S1, 9-13

\title{
Metabolic response to malnutrition: its relevance to enteral feeding
}

\author{
A H G LOVE \\ Department of Medicine, Queen's University, Belfast, Northern Ireland
}

SUMMARY Malnutrition results in a wide variety of metabolic responses, depending on circumstances, from reactions to pure deprivation of nutrients to include the added stress of injury and sepsis. Important differences of response exist between adults and children. Weight loss with changes in carbohydrate, fat, and protein metabolism are well documented. Disturbances of fluid and electrolyte balance are newer areas of interest as are changes in requirements for micronutrients such as trace metals. Many of these metabolic changes are under hormonal control.

The intestinal tract shares in the response to malnutrition, and the consequent changes in mucosal function determine the ability of the intestine to handle enteral feeds. Such a route for nutritional support is important in protecting intestinal function not only in absorption but also in hormone production. Enteral feeding is increasingly having an important role in the interactions between acute diarrhoeal disease and malnutrition.

The clinical circumstances in which malnutrition may arise vary enormously and will influence both the signs and the metabolic responses: primary protein calorie deprivation is common because of environmental forces in many countries; secondary semistarvation is often found in patients with cancer cachexia or the cachexia of other chronic diseases, those with anorexia nervosa, and inpatients, who for one reason or another can take little by mouth. In addition to inadequate supply, there may also be the added metabolic insult of the catabolic process of injury and sepsis. Furthermore, the responses may differ between adults and children extending from weight loss to failure of growth, and in extreme forms, the protein calorie deprivation syndromes of kwashiorkor and marasmus.

Earlier work in this area has concentrated on deficiency of macronutrients, but with the advent of new techniques and the application of parenteral nutrition the importance of essential fatty acids and various micronutrients is being recognised.

When placed in a situation of nutritional deprivation, the body undergoes a series of changes that can be divided into three stages: (i) depletion of reserves; (ii) metabolic adaption; (iii) deterioration and ultimate death. The rate of evolution of these stages

Correspondence to: Professor A H G Love, Department of Gastroenterology, Royal Victoria Hospital, Grosvenor Road, Belfast, Northern Ireland, BT12 6BJ.

and the adaptive processes depend on the nutritional onslaughts. Responses to starvation and injury must be clearly distinguished but may coexist in any patient. Table 1 details the major features.

\section{Metabolic response to malnutrition}

BODY WEIGHT

Weight loss is perhaps the oldest and most commonly accepted sign of a tissue catabolism that

Table 1 Comparison of effects of starvation and injury

\begin{tabular}{|c|c|c|}
\hline & Starvation & Injury \\
\hline Metabolic rate & Decreased & Increased \\
\hline Weight & Slow loss & Rapid loss \\
\hline Energy & Almost all from fat & $\begin{array}{l}80 \% \text { from fat; } \\
\text { remainder from } \\
\text { protein }\end{array}$ \\
\hline \multirow{3}{*}{$\begin{array}{l}\text { Nitrogen } \\
\text { Hormones }\end{array}$} & Losses reduced & Losses increased \\
\hline & $\begin{array}{l}\text { Early small increases } \\
\text { in catecholamines, } \\
\text { glucagon, cortisol, } \\
\text { growth hormone, } \\
\text { then slow fall }\end{array}$ & $\begin{array}{l}\text { Increases in } \\
\text { catecholamines, } \\
\text { glucagon, cortisol, } \\
\text { growth hormone }\end{array}$ \\
\hline & Insulin decreased & $\begin{array}{l}\text { Insulin increased but } \\
\text { relative insulin } \\
\text { deficiency }\end{array}$ \\
\hline $\begin{array}{l}\text { Water and } \\
\text { sodium }\end{array}$ & $\begin{array}{l}\text { Initial loss, late } \\
\text { retention }\end{array}$ & Retention \\
\hline
\end{tabular}


has lasted more than a few days. The gain or loss of body weight is the sum of changes in three body components - protein, fat, and water. Because body content and daily fluctuations for water are so much larger than for body fat or protein, weight change must be interpreted with this in mind, particularly as handling of water and electrolytes may be abnormal in the malnourished state.

\section{CARBOHYDRATE METABOLISM}

Glucose occupies a central role in carbohydrate metabolism. ${ }^{1}$ It serves as an optimal fuel for many tissues and an obligatory fuel for brain, red cells, and renal medulla. The circulating blood glucose would sustain these functions for only a few hours without calling on reserves. Reserves are found in the form of glycogen in many tissues, but only the liver can use this to provide new circulating glucose. This reserve in the absence of other sources would run out after about 12 hours. ${ }^{2}$ Amino acids are other major glucose precursors.

Recently it was shown that alanine is quantitatively the most important of the amino acids as a gluconeogenic precursor. ${ }^{3}$ It is derived from the animation of pyruvate in peripheral tissues, particularly muscle; but half of the amino acid groups released from muscle are in the form of alanine. An important fraction of alanine is also derived from glutamine metabolism in the gut. Intestinal mucosal integrity therefore contributes to this pathway. The final precursor is glycerol released from adipose tissue. Under normal circumstances this is a minor contributor to glucose production and only assumes importance in chronic deprivation. If starvation continues, glycogen stores are exhausted and gluconeogenesis becomes the sole source of glucose. Utilisation of tissue glucose falls as a result of inhibition by fatty acids and ketone bodies. ${ }^{4}$ The brain adapts to ketone body utilisation, and glucose requirements decrease further. Amino acids are conserved with lactate pyruvate and glycerol contributing carbon fragments. The serum glucose concentration falls slightly.

\section{PROTEIN METABOLISM}

Unlike carbohydrate, which is in limited reserve as glycogen, and fat, which has large reserves, there is no reserve of protein. Every molecule is performing a vital function, whether it is actin or myosin, part of the somatic protein compartment, or any one of the hundreds of visceral proteins. This includes the proteins of liver, kidney, and gut, as well as antibodies, enzymes, leucocytes, blood proteins, and other essential tissues. Tissue proteins are continually being synthesised and degraded. In a normal adult obligatory nitrogen loss of $50-60$ $\mathrm{mg} / \mathrm{kg} /$ day occurs in a protein free diet. Overall, protein synthesis rates in man range from 2 to 5 $\mathrm{g} / \mathrm{kg} /$ day: this is approximate due to difficulties in methodology. ${ }^{5}$ It is generally agreed that in protein calorie malnutrition the rate of catabolism of albumin is reduced to about half of the rate found after recovery. ${ }^{6}$ Globulins are probably unaffected by nutritional state. ${ }^{7}$ Plasma transferrin concentration is severely reduced in malnutrition and is due to a decreased rate of synthesis. Total body protein turnover studies indicate up to $30 \%$ reduction after five to six weeks on low protein diets. In the presence of injury or sepsis increased rates of turnover exist. Protein breakdown also seems to respond to changes in ketone body concentrations when these are high, such as, in starvation, when protein breakdown is inhibited. These interrelations are important in determining nutritional support programmes. $^{8}$

\section{LIPID METABOLISM}

Lipids provide several useful fuels that are used directly by tissues - that is, non-esterified fatty acids (NEFA) and ketone bodies. Triglycerides are also distributed throughout the body by means of the lipoprotein carrier system and either used for storage or degraded to fatty acids and glycerol. Normally, there is a continuous cycle in the adipocyte, whereby triglycerides are broken down (lipolysis) through the action of lipase and resynthesised. Lipolysis forms NEFA and glycerol. This is an important fuel source. They may be converted by the liver to ketone bodies. Ketone bodies cannot be used by the liver for fuel and enter the circulation for oxidation elsewhere - for example, the brain in prolonged starvation. The main importance of fat as fuels is their role in preserving glucose in the starved state for use by obligatory tissues. This indirectly spares protein. In catabolic states, however, this protein sparing capacity is lost.

\section{ENERGY METABOLISM AND THERMOREGULATION} Many of the clinical features of severe malnutrition, such as physical inactivity, unresponsive emotional state, bradycardia and decreased body temperature, are consistent with decreased metabolic rate. Recent studies have confirmed this position and even indicated particular organ contributions to basal metabolic rate. The picture is changed considerably by the presence of injury or sepsis when hypermetabolism is operative. The starvation studies conducted by Keys ${ }^{10}$ show that when body weight decreased by $25 \%$ the basal metabolic rate fell by about $40 \%$. After surgery or major infection, such as peritonitis, the expenditure may increase by $30-50 \%$ above predicted levels. The largest 
increases are seen in the previously well nourished, heavily muscled young adult male. Currently there is much debate as to the desirability or even the possibility of nutritional support to replace these deficits.

FLUID, ELECTROLYTE, AND MINERAL

METABOLISM

The average adult weighing $70 \mathrm{~kg}$ has an approximate composition of $40 \%$ organic material, $55 \%$ total body water, and $5 \%$ minerals - mostly in the skeleton. Obvious changes in body fluid content are seen in the classical oedematous state of kwashiorkor. The exact mechanism of oedema formation is still being debated. ${ }^{11}$ Interest is now focusing on the distribution of fluid between compartments and shifts into the cellular space in protein calorie malnutrition. Studies ${ }^{12}$ on cell membrane function in relation to sodium potassium pump activity have shown important changes in sodium distribution. Sodium enters the cells ${ }^{13}$ and the extracellular fluid shows hypoosmolarity. ${ }^{14}$ Potassium loss is a constant feature and may be helped by protein catabolism and deficient energy sources.

It is now being recognised that other minerals are important in the response and treatment of malnutrition. Magnesium deficiency is not accurately reflected by serum concentrations. ${ }^{15}$ Zinc has been shown to be extremely important in many cellular functions and may be critical in protein anabolism during recovery. ${ }^{16}$ In catabolic states zinc is lost in increasing amounts.

\section{Hormone changes}

The complex metabolic responses in malnutrition are controlled by a wide variety of hormones. Insulin predominates in anabolism, while cortisol, catecholamines, and glucagon are catabolic and are the hormones of fuel mobilisation. Growth hormone contributes to protein synthesis, and thyroid hormones probably "set" metabolic rates.

In carbohydrate metabolism insulin promotes glucose entry into cells and is therefore vital in the

Table 2 Changes in body fluids and electrolytes in malnutrition

\begin{tabular}{ll}
\hline Total body water & Increased \\
Extracellular water & Increased \\
Total body potassium & Decreased \\
Total body sodium & Increased \\
Total body magnesium & Decreased \\
Plasma potassium & Possibly low \\
Plasma sodium & Tends to be low \\
Plasma magnesium & Normal to low \\
\hline
\end{tabular}

response to glucose loads and in promoting glycogen deposition. The differences in response to parenteral and enteral calorie delivery may be extremely important, particularly in situations demanding high glucose loads. It is important to distinguish between conditions of starvation in which insulin secretion is depressed from those of injury and stress in which insulin resistance is common.

Glucagon and cortisol produce the opposite effects of insulin. Glucagon exerts its effects mainly on the liver, while cortisol has a major role in extra hepatic metabolism. The action of glucagon is probably short lived, while cortisol has long action. It is the most important proteolytic hormone and increases the transfer of glucogenic amino acid to the liver. The inhibition of glucose entry into cells has a major role in contributing to insulin resistance of stress.

The enteral route of nutrition provides the normal stimulus to hormone release in that it stimulates the "entero insular axis", and other gut hormones which may influence metabolic processes. It is probably quite important that these hormones accompany absorbed nutrients in the portal venous drainage to the liver for simultaneous first clearance in that organ. As yet, little is understood of these important relations in malnutrition.

Most of the studies on protein calorie malnutrition have reported changes in plasma or serum concentration of hormones. These measurements are based on difficulties of measurement and interpretation due to primary changes in protein metabolism. ${ }^{17}$ Plasma concentrations may not represent biologically active forms of hormone and can only be the net difference between rate of secretion and metabolic clearance. There is evidence to suggest that malnutrition may not only change metabolic factors governing hormone production and destruction, but that there may also be concomitant structural changes in endocrine glands. This has been shown in relation to the deficient insulin secretion in protein calorie malnutrition. ${ }^{18}$

\section{Derangement of gastrointestinal function in primary malnutrition}

Disorders of structure and function have been reported in association with malnutrition, quite apart from those changes perhaps already existing as a result of disease. Table 3 lists these changes.

The basic defect is a decrease in absorptive surface area because of decreased cell proliferation, migration, and maturation within the crypt villous unit. These changes result in an appreciable decrease in absorption of nutrients as part of the end stage of digestion and transport. As a result of 
Table 3 Gastrointestinal changes in malnutrition

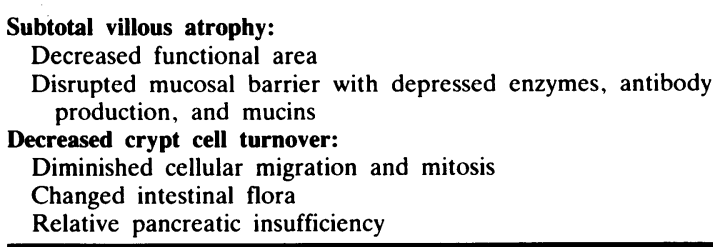

decreased energy available for normal cell turnover, migration, and maturation, the intestine can no longer operate optimally as either a digestive organ or an organ of protection. Because of the variability in degrees of nutrient intake and malnutrition, the spectrum of intestinal change is wide. In relation to enteral nutrition it is important to note that mucosal change correlates best with deprivation of luminal nutrition, rather than overall nutritional state. It is therefore part of the intestinal adaptive process.

In addition to the morphological changes seen in malnutrition, there are important changes in digestive activity. Pancreatic exocrine deficiency has been described. ${ }^{19}$ There is depression of resting and stimulated pancreatic enzyme activities, including those of lipase, trypsin, and amylase. ${ }^{20}$ These studies suggest that pancreatic function is seriously impaired. Epithelial function is also depressed, with a reduction in lactase absorption and decreased lactase activity in mucosal biopsies. ${ }^{21}$ These changes are extremely important for determining the composition and quantity of enteral feeding in the malnourished state.

The importance of enteral nutrition is highlighted by the part it plays in maintaining mucosal function. The factors influencing mucosal adaptive processes have been reviewed by Dowling, ${ }^{23}$ and it is generally recognised that luminal nutrition is of major importance (Table 4).

Specific nutrients have been shown to stimulate mucosal function - long chain triglycerides,${ }^{24}$ sugars, and amino acids. ${ }^{25}$ These studies indicate that substrates, which are absorbed across the mucosal cells either actively or passively, both metabolised or non-metabolised, can stimulate morphological and functional adaption. The passage of substrate

Table 4 Factors influencing intestinal adaption

\begin{tabular}{ll} 
Major factors: & $\begin{array}{l}\text { Luminal nutrition } \\
\text { Pancreaticobiliary secretions } \\
\text { Enteric hormones }\end{array}$ \\
Minor factors: & Mucosal blood flow \\
& Neural effects \\
\hline
\end{tabular}

into or through the mucosa seems to trigger the hyperplasic response. This process is deficient in parenteral nutrition.

Evidence suggests that nutrient absorption releases enteric hormones that are important in metabolic regulation and which may also promote trophic changes in the mucosa itself. Such hormones include gastrin, secretin, glucagon, gastric inhibitory polypeptide, and indirectly, insulin. There is substantive evidence to implicate enteroglucagon in an adaptive process. ${ }^{27}$ Enteral nutrition, therefore, not only influences mucosal cell function directly but can also release important enteric hormones that subsequently affect mucosal performance and intermediary metabolism.

\section{Diarrhoea and malnutrition: important interactions}

The classic work of Scrimshaw et al ${ }^{28}$ suggested that malnutrition and infections, such as diarrhoea, operate in a synergistic manner. Malnutrition predisposes the host to diarrhoea and, conversely, diarrhoea exerts an adverse effect on nutritional states.

Previous research may have overemphasised the symptom of diarrhoea, rather than the nutritional consequence of the diarrhoeal infections. Oral cocktails have now been developed that play a major part in maintaining fluid balance and reducing diarrhoea. ${ }^{29}$ Improved calorie and protein intake during acute disease by enteral feeding deserves more attention. Efforts to minimise anorexia and improve feeding during acute disease have been beneficial in the delivery of macronutrients and by helping to induce intestinal enzymes, spare protein loss, and reduce the loss of body mass. ${ }^{30}$ Because lactose intolerance is common, much controversy exists with regard to the wisdom of infant feeding in acute diarrhoeal disease. This is an area requiring further study. There is no doubt about the need for high calorie and protein intake during convalescence, which is best accomplished by aggressive compensatory nutritional support.

\section{References}

1 Johnston DG, Alberti KGMM. Carbohydrate metabolism in liver disease. Clin Endocrinol Metab 1976; 5(3): 675-702.

2 Alberti KGMM. Metabolic pathways - hormonemetabolite interrelations. In: Karran SJ, Alberti KGMM, eds. Practical nutritional support. Tunbridge Wells: Pitman Medical, 1980: 5-19.

3 Felig P. The glucose-alanine cycle. Metabolism 1972; 22: 179-207. 
4 Newsholme EA. Carbohydrate metabolism in vivo: regulation of the blood glucose level. Clin Endocrinol Metab 1976; 5(3): 543-78.

5 Waterlow JC, Sender PM. Effect of injury on protein requirements. In: Wilkinson $\mathrm{AW}$, Cuthbertson $\mathrm{D}$, eds. Metabolism and the response to injury. Tunbridge Wells: Pitman Medical, 1976: 215-28.

6 Picou D, Waterlow JC. The effect of malnutrition on the metabolism of plasma albumin. Clin Sci 1962; 22: 459-68.

7 Cohen S, Hansen JDL. Metabolism of albumin and $\gamma$ globulin in kwashiorkor. Clin Sci 1962; 23: 351-9.

8 Blackburn GL, Kaminski MV. Nutritional assessment and intravenous support. In: Karran SK, Alberti KGMM, eds. Practical nutritional support. Tunbridge Wells: Pitman Medical, 1980: 166-89.

9 Alberti KGMM. Metabolic pathways-hormonemetabolite interrelations. In: Karran SJ, Alberti KGMM, eds. Practical nutritional support. Tunbridge Wells: Pitman Medical, 1980: 5-19.

10 Keys A, Brozek J, Henschel A, Mickelsen O, Taylor HL. The biology of human starvation. Minneapolis: The University of Minnesota Press, 1950.

11 Klahr S, Alleyne GAO. Effects of chronic proteincalorie malnutrition on the kidney. Kidney Int 1972; 3: $129-41$.

12 Patrick J, Hilton PJ. The response of the human leucocyte to alterations in extracellular osmolality. Clin Sci 1973; 44: 457-65.

13 Patrick J. Physiological aspects of nutrition. Proceedings of the 10th International Congress of Nutrition, Kyoto, Japan: International Union of Nutritional Sciences, 1974: 161-2.

14 Kaye M. An investigation into the cause of hyponatremia in the syndrome of inappropriate secretion of antidiuretic hormone. Am J Med 1966; 41: 910-26.

15 Alleyne GAO, Hay RW, Picou DI, Stanfield JP, Whitehead RG. The biochemistry and pathophysiology of severe protein-energy malnutrition. Protein energy malnutrition. London: Arnold, 1977.

16 Golden MHN, Golden BE. Trace elements - potential importance in human nutrition with particular reference to zinc and vanadium. Br Med Bull 1981; 37: 31-6.

17 Pimstone BL. In: Gardener LI, Amacher P, eds. Endocrine aspects of malnutrition. Santa Yuez: Kroc Foundation, 1973: 150-65.
18 Hadden DR. Glucose, free fatty acid, and insulin interrelations in kwashiorkor and marasmus. Lancet 1967; ii: 589-92.

19 Badr El-Din MK, Aboul Wafa MH. Pancreatic activity in normal and malnourished Egyptian infants. $J$ Trop Pediatr 1957; 3: 17.

.20 Barbezat GO, Hansen JDL. The exocrine pancreas and protein-calorie malnutrition. Paediatrics 1968; 42: 77-92.

21 Torun B, Solomons NW, Caballero B, Flores Huerta S, Orozco G, Pineda O. The effect of dietary loctose on the early recovery from protein-energy malnutritionII-indices of nutrient absorption. Am J Clin Nutr 1984; 40: $601-10$

22 Feldman EJ, Dowling RH, McNaughton J, Peters TJ. Effects of oral versus intravenous nutrition on internal adaption after resection. Gastroenterology 1976; 70: 712-19.

23 Dowling RH. Small bowel adaption and its regulation. Scand J Gastroenterol 1982; 17 (suppl 74): 53-74.

24 Brey VL, Garofalo C, Greenberg GR, Morin CL. The adaption of the small intestine after resection in response to free fatty acids. Am J Clin Nutr 1984; 40: $1235-42$.

25 Spector MH, Levine GM, Deren JJ. Direct and indirect effects of dextrose and amino acids on gut mass. Gastroenterology 1977; 72: 706-10.

26 Dworkin LD, Levine GM, Faber HJ, Spector MH. Small intestinal mass of the rat is partially determined by indirect effects of luminal nutrition. Gastroenterology 1976; 71: 626-30.

27 Jacobs LR, Polak JM, Bloom SR, Dowling RH. Intestinal mucosal and fasting plasma levels of immunoreactive enteroglucagon. In: Robinson JWC, Dowling RH, Reicken ED, eds. Falk symposium 30: mechanisms of intestinal adaption. Lancaster: MTP Press, 1982: 231-40.

28 Scrimshaw ND, Taylor CE, Gordon JE. Interactions of nutrition and infection. Monograph series No 57. Geneva: WHO, 1968.

29 Nalin DR, Cash RA, Rhaman ASMM. Oral maintenance therapy for cholera patients in all age groups. Bull WHO 1970; 43: 361-8.

30 Rosenweig NS. Diet and intestinal enzyme adaption: Implications for gastrointestinal disorders. Am J Clin Nutr 1975; 28: 648-55. 